\title{
UM DISCURSO AFINADO: 0 EPISCOPADO CATÓLICO FRENTE à "POLIIIICA" E AO "SOCIAL"
}

\author{
Ernesto Seidl \\ Universidade Federal de Sergipe - Brasil
}

Resumo: $O$ artigo aborda as relações entre o episcopado católico brasileiro e seu posicionamento como grupo de representação frente ao universo da "política" e do "social". A análise procura evidenciar, por um lado, a lógica dos mecanismos de produção de representações do alto clero como grupo homogêneo destinado a produzir mensagens unívocas para públicos variados e, por outro lado, um conjunto variado de estratégias de elaboração e apresentação de discursos institucionais adequados à "realidade do país" e do "mundo" e que visam a legitimar a posição da Igreja como instituição capaz de falar com autoridade sobre ampla gama de temas.

Palavras-chave: elite eclesiástica, episcopado, Igreja católica, política.

Abstract: This article analyses the relations of Brazil's Catholic bishops and their position, while a representation group, regarding "political" and "social" issues. The purpose of the study is twofold: it tries to cast light on the logic of the mechanisms which mold the representations of the Brazilian high clergy as a homogeneous group responsible for elaborating univocal messages to a heterogeneous public; and it tries to apprehend a vast set of strategies of making and presenting official well-adapted discourses to both Brazil's and the world's realities, as a way of legitimating the Church as an authority on a vast sort of subjects.

Keywords: Catholic Church, ecclesiastical elite, episcopal group, politics.

Eu não me considero progressista, mas também não acho que sou um conservador.

Eu acho que eu não sou conservador, muito menos acho que eu sou progressista. Eu acho que sou moderado. Eu acho que sou... (risos).

(Bispos diocesanos, ambos entre 65 e 70 anos de idade).

Horizontes Antropológicos, Porto Alegre, ano 13, n. 27, p. 145-164, jan./jun. 2007 
Este texto tem por objetivo central abordar as relações entre o episcopado católico e seu posicionamento como grupo de representação frente ao universo da "política” e do "social”. Num nível mais geral, as questões de pesquisa aqui tratadas relacionam-se com uma série de discussões sobre a estruturação, funcionamento e transformações da alta esfera eclesiástica no Brasil a partir da segunda metade do século passado. Dentre essas questões, também se coloca a das redefinições do espaço católico dentro do espaço do poder e, em especial, da dinâmica da esfera religiosa católica com a esfera da política e seus desdobramentos sobre os mecanismo de recrutamento e seleção das elites dirigentes da Igreja. ${ }^{1}$

A partir dessa problemática mais ampla, e inspiradas em indicações de estudos realizados em outros contextos (Bourdieu, 1971, 1996; Bourdieu; Saint Martin, 1987; Vassort-Rousset, 1986, 1987), algumas dimensões específicas foram exploradas pela análise e são aqui apresentadas seguindo dois eixos principais de interesse. Diferentemente de abordagens centradas no exame ou inventário das posições oficiais da alta hierarquia católica em relação à "política” e de suas variações ao longo do tempo (Azzi, 1978, 1981; Lima, 1979; Morais, 1982), ou então daquelas dedicadas a entender o "papel” ou a "função” da Igreja como instituição legitimadora ou contestadora do poder político estabelecido (Bruneau, 1974, 1985; Della Cava, 1978; Löwy, 2001; Mainwaring, 1989; Serbin, 2001), a perspectiva aqui empregada procura: por um lado, evidenciar a lógica dos mecanismos de produção de representações do alto clero como grupo homogêneo destinado a produzir mensagens unívocas para públicos variados e ao mesmo tempo garantir a imagem de unidade do próprio grupo e, por outro lado, lançar luz sobre um conjunto variado de estratégias de elaboração e apresentação de discursos institucionais que se pretendem adequados à "realidade do país” e do "mundo" e que visam a legitimar a posição da Igreja como instituição capaz de falar com autoridade sobre ampla gama de temas.

\footnotetext{
1 O material que deu origem a este trabalho faz parte de um empreendimento mais amplo de pesquisa conduzido sobre a estruturação institucional da Igreja católica no Estado do Rio Grande do Sul e, em especial, sobre a composição e transformações de sua elite dirigente ao longo da segunda metade do século XX. Os dados que serviram de base para o presente artigo foram reunidos, fundamentalmente, através de entrevistas com o conjunto de bispos (em atividade e eméritos) daquele estado em 2003 e de observações e interações de campo durante a 39a Assembléia Geral da Conferência Nacional dos Bispos do Brasil, realizada na localidade de Itaici, município de Indaiatuba (SP), entre 12 e 21 de julho de 2001. O conjunto dos resultados do trabalho encontra-se em Seidl (2003).
}

Horizontes Antropológicos, Porto Alegre, ano 13, n. 27, p. 145-164, jan./jun. 2007 


\section{Os bispos e a "política"}

Provavelmente nenhum outro tema seja tratado de modo mais homogêneo pelo alto clero católico no Brasil do que o que se refere às relações entre Igreja e "política"; em particular, entre o próprio episcopado e a "política". Situados numa posição do espaço eclesiástico exigindo alto grau de controle sobre a imagem de unidade do corpo religioso, esses especialistas do duplo sentido e do eufemismo manipulam de modo impressionante uma retórica uníssona ao discorrer sobre os limites entre o domínio “espiritual”, terreno legítimo de ação dos homens da Igreja, e o "temporal”, campo de atuação dos leigos. Na base do princípio de separação de "competências” invocado pelos membros da alta hierarquia eclesiástica está a divisão fundamental que marca as diferenças entre um corpo de peritos na manipulação dos bens espirituais e uma clientela "profana” desprovida desse capital de saber religioso. Porém, como mostram Bourdieu (1996) e Bourdieu e Saint Martin (1987), é mais precisamente na necessidade de manutenção da unidade tanto do quadro profissional religioso da instituição quanto do de seus clientes, reais ou potenciais - a "unidade da Igreja”, como um "todo”, ou como "família” - que se encontra a lógica que justifica a terminante recusa a tomadas de posição "excludentes”, “opositoras”, “divisoras” - próprias às ideologias políticas e aos partidos.

Em conformidade com o argumento teológico de não-discriminação dos indivíduos passíveis de integrar o grupo cristão, vale dizer, a pretensão de "universalidade do apelo evangelizador”, o rechaço sistemático à adesão partidária ou ideológica encontrado, sem exceção e num vocabulário invariável, nos depoimentos de prelados atuando no Rio Grande do Sul é construído em oposição a um conjunto de princípios ético-religiosos que se propõe estar acima das opções “políticas”, as quais, segundo os bispos, “dividem”, “desunem”, “comprometem”. Assim, essa neutralização das posições políticas dos líderes eclesiásticos se opera através de uma dicotomia entre valores católicos de caráter "geral”, “universal”, “comum”, “mais elevado”, e aqueles de caráter "particular”, “parcial”, “partidário” (no sentido menos consagrado do termo). É desse modo, por exemplo, que, se os interesses sociais expressos nas ideologias dos partidos políticos necessariamente opõem os indivíduos e os colocam em situação de competição - fundamentalmente, o que se entenderia pela noção de "política” -, à Igreja cabe o papel de se manter afastada das particularidades contingentes e de defender princípios “superiores” sem identificação ideológi- 
ca, ou seja, a “política com ‘p’ maiúsculo”, “no sentido grande”, “a verdadeira política” - expressões muito recorrentes no repertório acionado pelos membros do episcopado.

Outro aspecto que eu gostaria também de tocar. Como o senhor vê a relação do clero, da Igreja, com a política?

A política, para mim, é a ciência do bem-comum; então, nós devemos estar envolvidos nisso. Sou radicalmente contra a participação na política partidária, porque a nossa função de bispo, de padre, de igreja, é unir e não dividir, e se eu tomo um partido, automaticamente eu estou dividindo uma comunidade, uma paróquia, uma diocese, então eu sou radicalmente contra a participação de padre na política partidária. Eu creio que deve existir muito cuidado e muito equilíbrio, não que a gente deve se omitir, mas qualquer coisa que a gente diga imprudentemente pode causar uma divisão que nunca mais se recupera. [...] nós temos que dar princípios, a aplicação concreta dos princípios é o leigo que tem que fazer. (Bispo diocesano, 71 anos, sagrado em meados dos anos 1980).

A missão primeira da Igreja e do bispo é a evangelização; o problema é podermos fazer uma evangelização abstrata. Então, se o povo está sofrendo, não podemos ignorar isso. [...] Mas eu creio que, politicamente, o bispo e o padre não devem se posicionar no partido político. Devem se posicionar no partido do bem-comum, que está acima de qualquer partido político, o bem-comum deve estar sempre para que haja a verdadeira política da educação, a verdadeira política da saúde, a verdadeira política dos meios de comunicação, a verdadeira política de habitação, a verdadeira política da distribuição da terra, ou agrária, que haja uma política do trabalho, eu acho que isto tende a estar a favor dos necessitados. A gente tem que se policiar nos partidos políticos; às vezes vai doer, vão nos classificar; deixe que classifique; mais tarde, vão ver que a gente não fez nada mais que a obrigação da gente. (Bispo diocesano, 65 anos, sagrado em fins da década de 1980).

Por outro lado, se a “política” declarada como opção ideológica faz parte do universo discursivo episcopal somente pela negação de sua legitimidade na esfera eclesiástica, as manifestações públicas da hierarquia sobre a ordem social, política e econômica do país e do mundo, sobre as “questões do momento”, enfim, sobre um enorme temário não enquadrado exclusivamente em assuntos consagrados da "espiritualidade", constituem tanto um dos instrumentos mais difundidos de explicitação do "ponto de vista” católico entre as principais disputas ideológicas vigentes quanto, sem dúvida, uma das tarefas mais legítimas no 
exercício da função episcopal contemporânea. Dentre os efeitos da reorientação conciliar de "inculturação" do catolicismo nas diferentes "realidades sociais" e as tentativas de um novo enquadramento católico da vida social em suas dimensões mais diversas, a intensificação das manifestações de autoridades religiosas a respeito de um mundo crescentemente secularizado e complexo aparece, juntamente com as profundas modificações nas formas de celebração litúrgica, como peça central na atualização das relações entre especialistas e leigos. Se a missa e os sacramentos passariam a ser ministrados nos idiomas de cada país e se tornariam mais facilmente acessíveis aos fiéis, também os profissionais da religião deveriam procurar aproximar-se de sua clientela através de uma linguagem adequada a audiências crescentemente urbanas, escolarizadas e difusas.

De fato, a imposição de uma competência religiosa baseada na competência escolar, ou intelectual, configura seguramente uma das dimensões mais centrais dos mecanismos de regulação do espaço católico. $\mathrm{O}$ aumento considerável dos investimentos na aquisição de diplomas acadêmicos por agentes institucionais como base para ocupação de cargos superiores - perceptível, sobretudo, entre os membros do episcopado -, faz ver com clareza o espaço conferido à cultura escolarmente legitimada dentro dos instrumentos de adaptação da Igreja a públicos mais urbanos e escolarizados. Não apenas a expansão da oferta de formação religiosa, mas também a diversificação do tipo de qualificação e das formas de saber, na qual se destaca a incorporação de áreas “não-tradicionais” da teologia e disciplinas "profanas”, apontam para essa direção. Uma das conseqüências de maior visibilidade da centralidade adquirida pelo saber escolar sobre as formas de dominação simbólica da Igreja foi justamente uma redefinição nos modos de exercício da autoridade religiosa, percebida com mais intensidade no âmbito das funções "intelectuais". Na esteira de Vaticano II, a readequação dos instrumentos pedagógicos religiosos pela aproximação com a esfera de produção de conhecimento científico, notadamente faculdades e universidades, marcou em definitivo o deslocamento do espaço de reprodução intelectual do corpo religioso das instituições escolares consagradas (de formato "rural”, "fechadas"), para ambientes muito pouco diferenciados do mundo escolar leigo. ${ }^{2}$

\footnotetext{
Nesse sentido, ver Seidl (2003), em especial o Capítulo III, “A Igreja em Movimento: dos Seminários aos Institutos de Teologia”, e Rousseau (1982).
}

Horizontes Antropológicos, Porto Alegre, ano 13, n. 27, p. 145-164, jan./jun. 2007 
A composição homogênea da "agenda” católica e sua coincidência parcial com a "agenda social e política" do país têm estreita conexão com a significativa mudança de posição da Igreja brasileira no espaço social a partir do regime militar instalado em 1964 e das transformações sociais ocorridas nas últimas três décadas. ${ }^{3}$ Notadamente, o papel da Conferência Nacional dos Bispos do Brasil (CNBB) - com todas suas instâncias especializadas assessoradas por cientistas sociais e outros peritos sociais, leigos e religiosos, encarregados de subsidiá-la com um saber academicamente chancelado - como órgão oficial da hierarquia favorecendo tomadas de posição em bloco foi decisivo na elaboração de um discurso "crítico" e na imposição de uma imagem do episcopado como grupo autorizado a falar sobre as "questões do país”. ${ }^{4}$ As freqüentes "declarações” e "documentos" assumidos pela entidade representativa dos bispos e reconhecida por Roma fornecem aos prelados uma pauta oficial da instituição em torno da qual, em maior ou menor grau, os líderes hierárquicos elaboram suas orientações no nível diocesano, sempre sob o risco de desafiar a “problemática legítima” (Bourdieu, 1979).

\section{CNBB: "uma opinião que conta"}

Como fica a posição da CNBB quando é chamada a se manifestar sobre a política em geral?

Mesmo que ela não queira, todo o mundo procura a CNBB para ver o que ela pensa; a CNBB é um referencial natural no Brasil, hoje; então, não importa se você quer declarar ou não, eles vão lá e começam a perguntar: "o que o senhor acha do Fernando Henrique?”, “o que o senhor achou do apagão?”, “o que o senhor achou disso e daquilo”. Então, você é obrigado a entrar dentro destas problemáticas para poder dar um sentido e uma opinião razoável para o povo. Não é que tu queiras fazer

3 A literatura pertinente é unânime ao demonstrar a inflexão significativa na posição oficial do alto clero frente ao regime militar a partir da década de 60 e na afirmação da instituição como espaço de oposição e interlocução legítima com representantes dos governos militares. Em especial, ver Azzi (1981), Bruneau (1974, 1985), Della Cava (1975, 1978), Mainwaring (1989), Marin (1995), Morais (1982) e Serbin (2001).

${ }^{4}$ Sobre o surgimento da Conferência Nacional dos Bispos do Brasil e as principais tomadas de posição da instituição frente à “política” e ao “social”, ver Morais (1982).

Horizontes Antropológicos, Porto Alegre, ano 13, n. 27, p. 145-164, jan./jun. 2007 
isso. Tu queiras ou não queiras, eles vêm. Claro que eu podia ser indelicado e dizer que não falo disso, só falo de Jesus Cristo; mas aí o pessoal ia dizer: “este bispo aí está fora do mundo. Está fora”. (Bispo diocesano, ex-presidente da CNBB).

Então, o exercício... mas eu vou te dizer outra coisa: o bispo não é bispo como ele gostaria de ser, e tantas vezes ele tem que assumir, como a nossa CNBB, e assim por diante. Eu acho que não é que nós gostamos de fazer tantos pronunciamentos. Eu acho que os leigos deveriam fazer, os outros deveriam fazer, mas se não há quem faça, a gente se obriga, na conjuntura, os tempos obrigam. Eu acho que eu não fui o bispo que eu gostaria. Também por isso... mas as circunstâncias obrigaram, e aí, com isso, eu agradeço a Deus. (Bispo diocesano, 65 anos, sagrado no início dos anos 1970).

Respaldados pela condição de líderes institucionais de uma religião dominante e com estruturas múltiplas por todo o Brasil, dotados de recursos culturais crescentemente legitimados pelo sistema escolar e treinados no uso da palavra escrita e falada, os bispos recorrem de modo regular à divulgação de uma visão de mundo da Igreja que se pretende “atualizada” e seja capaz de mobilizar públicos variados. Em que pesem as diferenças de intensidade e estilo de intervenção, ligadas a diferentes origens e trajetórias, ${ }^{5}$ os pontos abordados nos textos e alocuções pelos prelados atualmente em função no Estado do Rio Grande do Sul, assim como suas declarações recolhidas em nossas entrevistas, ${ }^{6}$ não apresentam praticamente nenhuma variação substantiva. Ao lado das análises de fundo “espiritual”, como aquelas centradas em comentários de passagens do evangelho, no esclarecimento da doutrina ou em celebrações do calendário cristão, uma ampla temática "social” e “contemporânea” - composta por temas como “política econômica”, “meio ambiente”, “miséria”, “dívida

5 O acesso e o uso da palavra, a intimidade com os meios de comunicação e a abordagem de temas mais distantes do universo estritamente espiritual relacionam-se diretamente com a realização de trajetórias religiosas favorecendo não apenas o acúmulo de um capital de autoridade cultural ligado a posse de recursos escolares - elemento, sem dúvida, fundamental -, mas igualmente de disposições sociais que tendem a tornar usual e familiar as situações de interação com a imprensa, com grandes eventos e grandes públicos, a participação em debates e eventos, organizados pela Igreja ou não.

6 Baseamo-nos principalmente em artigos publicados semanalmente na imprensa e em textos e notas enviados via Internet pelo serviço de comunicação das dioceses do Rio Grande do Sul. De modo menos sistemático, também recebemos esse tipo de serviço de dioceses de outros estados.

Horizontes Antropológicos, Porto Alegre, ano 13, n. 27, p. 145-164, jan./jun. 2007 
externa”, “violência”, “reformas políticas”, “drogas”, “eleições” - compõe o outro eixo principal das “preocupações” legítimas das lideranças eclesiásticas. Embora todos os prelados disponham de meios específicos de comunicar a "palavra da Igreja” em suas dioceses, aqueles desfrutando de maior notabilidade em função do tipo de diocese e dos cargos que ocupam ou ocuparam tendem a expor com maior freqüência a posição eclesiástica sobre os temas “polêmicos” da “conjuntura”. É em especial na arquidiocese de Porto Alegre e em algumas poucas dioceses centrais do estado, lideradas por religiosos dispondo dos recursos exigidos pelo posto e favorecendo o acúmulo de um capital de autoridade - títulos escolares importantes, estadas no exterior, habilidade de comunicação, passagens por cargos nacionais -, que o episcopado gaúcho tem suas tomadas de posição de maior repercussão veiculadas em nível estadual ou mesmo nacional. É assim, por exemplo, que, cerca de um mês antes da realização de eleições presidenciais no Brasil, na condição de liderança da instituição católica no Rio Grande do Sul, com sede na capital, contando com a maior estrutura religiosa do estado e com uma "história" de forte "presença na sociedade”, o arcebispo de Porto Alegre - licenciado em direito canônico por Roma, ex-funcionário do Vaticano e autor de vários livros de temática ampla - reúne a imprensa para expressar a "posição oficial” da Igreja local sobre as reformas do governo brasileiro. O texto abaixo foi divulgado pela assessoria de imprensa da Cúria Metropolitana, órgão muito ativo ligado à Pastoral da Comunicação da Arquidiocese, sob direção de um padre jornalista:

\section{Arcebispo lança cartilha sobre Reformas}

O Arcebispo de Porto Alegre lança na próxima segunda-feira, 1ํo de Setembro [de 2002], a Cartilha das Reformas Brasileiras. Dom Dadeus Grings reúne-se com a imprensa, às 14h, na Cúria Metropolitana. O texto apresenta a posição oficial da Igreja da Arquidiocese sobre as reformas em andamento e as projetadas pelo atual Governo Federal. Para o Arcebispo, falta abertura para debate maior com a sociedade antes de submeter os projetos à apreciação do poder legislativo. Dom Dadeus disse que todos os cidadãos têm o direito de participar dessas discussões. Ele afirmou que elas não podem ficar restritas a uma pequena elite, nem vinculadas ao debate exclusivo dos políticos de profissão. O texto apresenta posicionamento oficial da Igreja local sobre as reformas já em discussão no Congresso Nacional e sugestões para o debate da sociedade sobre as reformas projetadas como a política e a partidária. O Arcebispo disse que o material apresenta posicionamentos 
contundentes para estimular uma discussão séria sobre as alterações que a nação precisa fazer.

Fortemente assentado na idéia de unidade interna e de alinhamento com as diretrizes nacionais e com o Vaticano, o grupo de bispos rio-grandenses apresenta percepções que pouco divergem entre si quanto às estratégias de condução do trabalho religioso católico e à sua própria definição entre o episcopado nacional. Se, por um lado, a homogeneidade na composição social (ver Quadro 1) e étnica e na formação escolar do grupo - marcada pela "cultura romana" e a "fidelidade às orientações do papa" - tem peso decisivo na formação de uma postura episcopal compartilhada em altíssimo grau, por outro, não se pode desconsiderar os efeitos de manutenção das características do grupo através do controle sobre os mecanismos de recrutamento de seus membros. Majoritariamente oriundos de frações inferiores do colonato rural, de pequenos comerciantes e artesãos, quase todos sagrados após Vaticano II, de formação romanizada e praticamente não contando experiências de atuação profissional em contextos de carência extrema (periferias, favelas, missão em regiões em situação de penúria), os líderes eclesiásticos em pauta tendem a se situar numa posição de "virtude média”. Perto de realizarem uma auto-objetivação social, esses religiosos facilmente associam sua "origem simples" - porém longe da realidade de miséria conhecida em muitas outras regiões do país - na vida rural das colônias de imigrantes do estado a uma posição "equilibrada”, "moderada”, a qual, segundo eles, seria condizente com o universo "comunitário", de "menores injustiças e diferenças sociais", dentro do qual "se criaram” e onde atuam como religiosos.

Invocando com freqüência a situação de dioceses do Norte e Nordeste do país onde a precariedade das condições de vida justificaria um tipo de intervenção religiosa mais contundente em defesa da mudança social, em estilo "reivindicativo", os bispos gaúchos classificam-se numa posição "intermediária” que lhes permite exercer em posição vantajosa o delicado ofício de produzir mensagens para grupos sociais os mais diversos sem se comprometer exclusivamente com nenhum deles. Desse modo, embora sua retórica esteja perfeitamente afinada com a linha dominante no âmbito da Igreja brasileira e latino-americana - de uma "opção preferencial pelos pobres", ou de "Igreja dos oprimidos e desfavorecidos" -, todos esses religiosos insistem em matizar as implicações dessa tendência teológica em termos não-reducionistas. 
Quadro 1. Bispos gaúchos: profissão do pai

\begin{tabular}{|c|c|c|c|c|}
\hline $\begin{array}{l}\text { Profissão do pai / } \\
\text { período de sagração }\end{array}$ & até 1965 & 1966-1980 & 1981-2002 & Total \\
\hline Pequeno propriet. rural & $4(57,14 \%)$ & $7(58,33 \%)$ & $9(52,94 \%)$ & $20(55,55 \%)$ \\
\hline Médio propriet. rural & $1(14,28 \%)$ & - & $1(5,88 \%)$ & $2(5,55 \%)$ \\
\hline Grande propriet. rural & - & - & - & - \\
\hline Pequeno propriet. & - & - & $3(17,64 \%)$ & $3(8,33 \%)$ \\
\hline Peq. propr. comercial & - & $2(16,66 \%)$ & $1(5,88 \%)$ & $3(8,33 \%)$ \\
\hline Pequeno comerciante & - & - & - & - \\
\hline Pequeno empregado & - & $1(8,33 \%)$ & - & $1(2,77 \%)$ \\
\hline Artesão & $1(14,28 \%)$ & - & $1(5,88 \%)$ & $2(5,55 \%)$ \\
\hline Professor primário & $1(14,28 \%)$ & $1(8,33 \%)$ & $1(5,88 \%)$ & $3(8,33 \%)$ \\
\hline Professor universitário & - & - & - & - \\
\hline Funcionário público & - & - & $1(5,88 \%)$ & $1(2,77 \%)$ \\
\hline Técnico & - & $1(8,33 \%)$ & - & $1(2,77 \%)$ \\
\hline Total conhecido & $7(58,33 \%)$ & $12(75 \%)$ & $17(53,12 \%)$ & $36(60 \%)$ \\
\hline Total & 12 & 16 & 32 & 60 \\
\hline
\end{tabular}

Fonte: dados coletados pelo autor. 


\section{0 "vício" de ficar "em cima do muro"}

Então, eu tenho participado. Tenho, porém, um vício. Eu reconheço que tenho um vício. É o seguinte: eu não sou capaz de ler e me tornar adepto. Eu sou muito crítico, então eu sempre mantenho uma distância; digamos o seguinte: eu vou num intereclesial, mas eu não me boto dentro, assim, adepto, defensor intransigente; eu fico olhando, assim, e digo: "não, esse ponto aqui não está bem cuidado, esse eu acho melhor, aquele eu acho menos”. Isso é em tudo. Também nos movimentos; eu não sou de nenhum movimento, mas participo de todos. Por exemplo, eu participo dos cursilhos, eu participo da renovação carismática, mas não sou da renovação carismática, não sou dos foccolarianos. Participo, mas não sou, não me inscrevo entre os adeptos das Comunidades Eclesiais de Base, mas participo; até eu sou o bispo referencial, mas eu sempre mantenho uma certa distância, porque às vezes pode ser que me prejudique, e não é uma boa posição. [...]. O pessoal sempre me diz que eu fico em cima do muro. Não, eu quero ter uma certa distância para poder avaliar, avaliar. (Bispo diocesano, 69 anos, sagrado no começo dos anos 1980).

Se quanto mais elevada a posição na hierarquia, maiores os esforços cobrados de seu ocupante na elaboração de uma imagem de união do corpo institucional e na produção de mensagens para uma clientela abrangente, a liderança episcopal implica o domínio de uma retórica carregada de ambigüidades e subentendidos própria a conciliar os opostos e a não ser interpretada como “crítica”, mas como "sugestão" ou "ponto de vista”. 7 Quando solicitados a falar sobre sua "visão da Igreja”, "estratégias” e "desafios” para o catolicismo brasileiro no contexto atual, os prelados são unânimes em apresentar um discurso da “evangelização”, sua “tarefa primeira”, centrado na “dimensão social”

\footnotetext{
Como salientam Pierre Bourdieu e Monique de Saint Martin (1987, p. 2, tradução minha) já no início de seu trabalho sobre o episcopado francês: "De todos os grupos de representação, não há outro, sem dúvida, que trabalhe de maneira tão consciente e sistemática para moldar sua própria imagem do que o episcopado: isso inclui, certamente, o segredo que envolve as assembléias plenárias do episcopado e a prudência sibilina de declarações carregadas de ambigüidades estudadas e de subentendidos endereçados apenas aos capazes de entendê-los; o esforço em colocar nas posições mais em vista os personagens melhor preparados para encarnar a representação que o corpo quer ter e dar de si próprio [...]; e, sobretudo, a preocupação em atenuar as diferenças e os diferendos, assim como em manifestar a unidade e homogeneidade de um corpo que preza a idéia de pensar e agir 'colegiadamente'."
}

Horizontes Antropológicos, Porto Alegre, ano 13, n. 27, p. 145-164, jan./jun. 2007 
- designação oficial da Igreja para um conjunto de políticas institucionais, com respectivas estruturas, voltadas à assistência de públicos específicos e geralmente em situação desfavorável (sem-terra, operários, presidiários, crianças abandonadas, entre outros). Vazado em um vocabulário institucional, o discurso episcopal sobre os "pobres" e "necessitados" (a "sensibilidade para o social”, como costumam dizer) nunca aparece, no entanto, isolado de uma contextualização ampla de quais seriam os demais alvos da ação evangélica, ou mesmo do próprio questionamento da noção de "pobres” ("há que se ver o que se entende por pobres, porque eu não posso tomar apenas os pobres no sentido material, econômico, social”). Isto é, a recusa de se colocar unicamente em nome dos “pobres” ("trata-se de uma opção preferencial, não exclusiva”, como costumam repetir os prelados), ou de qualquer outro público definido, e de assim comprometer a pluralidade do apelo religioso católico, compõe um eixo central no esquema argumentativo desses profissionais versados em reproduzir fielmente a noção de “unidade na pluralidade”, válida tanto para os fiéis quanto para o próprio corpo eclesial.

\section{A "política" e o "social" transfigurados: a Assembléia Geral da CNBB}

A oportunidade privilegiada de aproximação com a alta esfera eclesiástica, de interação e observação diretas da elite hierárquica em carne e osso, reunida num espaço físico cujo acesso é altamente controlado, forneceu material dos mais valiosos para captar um conjunto de situações específicas e buscar entender parte dos elementos compondo o universo social e cultural da elite eclesiástica do Brasil atual. ${ }^{8}$ Sem a intenção de realizar uma ampla etnografia do alto clero católico, a estada entre os membros do episcopado brasileiro e de diversos outros agentes religiosos de posição variada no espaço católico (secretários episcopais, auxiliares, responsáveis leigos, jornalistas católicos,

${ }^{8}$ A decisão imprevista de viajar ao interior de São Paulo, as condições e estratégias de negociação de acesso aos espaços da assembléia e uma série de outros aspectos dessa etapa do trabalho de campo não podem ser aqui discutidos. Tais elementos são apresentados em detalhes em Seidl (2003), na seção 5.5, "Um sociólogo em meio aos bispos". Para uma discussão metodológica mais aprofundada sobre o conjunto de recursos usados na pesquisa, sugerimos consultar a seção V da introdução do trabalho, "Entrando no 'mundo da Igreja': etapas da investigação e seus aspectos metodológicos”.

Horizontes Antropológicos, Porto Alegre, ano 13, n. 27, p. 145-164, jan./jun. 2007 
organizadores, etc.), abriu uma série de perspectivas de análise quanto às hierarquias internas (não-oficiais) ao episcopado, às ambigüidades da relação com o poder e o uso da autoridade religiosa, às estratégias de produção de uma imagem e de mensagens de acordo com as percepções dominantes sobre a "Igreja brasileira” (“unida”, "preocupada”, "socialmente atuante”, "bem informada”, etc.), entre outros muitos aspectos. Assim, por exemplo, interessou à análise tomar em conta não apenas o que era dito durante os dias da assembléia, mas igualmente de que forma era dito, em que condições (quais espaços, para qual público, em qual ocasião) e por quem era dito. Por essa mesma operação, pôde-se delimitar, em negativo, parte do universo de interdições composto por risos, chistes, insinuações, metáforas e silêncios carregados de subentendidos e que igualmente revelavam muito sobre as formas de gestão da imagem do episcopado e da Igreja como um todo.

Embora a duração da assembléia fosse de dez dias, as reuniões de discussão concentraram-se em uma semana, descontando um dia livre (domingo) em que não houve atividades obrigatórias. Cada ano há um tema central pautando o encontro, o de 2001 sendo “A CNBB: vida e organização a serviço de Deus”, oportunidade em que seria discutido e votado o novo estatuto canônico da instituição. A intensidade das atividades distribuídas ao longo do encontro é bastante significativa e segue uma dinâmica muito semelhante à da vida religiosa de modo geral, com as primeiras orações cedo pela manhã e o jantar no início da noite. Os horários são bastante rígidos e as sessões em grandes ou pequenos grupos ocupam todas manhãs e tardes, com exceção do sábado de retiro e o domingo de folga. Todas reuniões que tratavam da discussão do estatuto da CNBB ou de algum outro tema privativo do episcopado (em torno de quatro) excluíram a presença de qualquer outro participante, inclusive assessores. Também diversas reuniões temáticas, de acordo com o engajamento pastoral ou com a região de atuação episcopal, aconteciam em pequenos grupos nas salas menores ao redor do auditório.

Há vários aspectos a comentar sobre as formas de condução das sessões, o comportamento dos clérigos e o ambiente geral desses momentos mais formalizados de encontro no auditório. Provavelmente, caso fossem eliminados os poucos rituais religiosos e alguns símbolos acompanhando todas sessões - orações inicial e final, representação de Nossa Senhora -, à primeira vista seria muito difícil distinguir a assembléia dos bispos de outras assembléias não-religiosas, tais como de partidos políticos ou de determinadas categorias profissio- 
nais (majoritariamente masculinas). As preocupações com procedimentos visando à "horizontalidade", "transparência” e "democracia” da assembléia ritos socialmente consagrados na esfera política e em diversos grupos -, de par com outras formas de eufemização das relações hierárquicas, são patentes desde o tom de voz e o vocabulário empregados, sobretudo pelos dirigentes da conferência, até a prática da consulta a toda assembléia a cada decisão, por mais trivial que pudesse parecer o assunto. A noção de igualdade de autoridade entre os prelados seguramente domina sua lógica de ação nessas ocasiões de congraçamento e exposição ao público, as manifestações de poder simbólico expressas, por exemplo, pela notoriedade de determinados bispos, sendo constantemente borradas por um tratamento uniforme por parte da mesa coordenadora, assim como pela ausência de prerrogativas ou deferências. A própria atitude dos bispos coordenadores da CNBB frente à assembléia parece revelar certo desconforto, a ver pela reduzida intervenção do presidente e a extrema cautela do bispo secretário-geral, principal animador das sessões, no encaminhamento das atividades.

O caráter “democrático” que se busca imprimir à instituição também aparece na possibilidade de qualquer prelado manifestar oralmente sua opinião na tribuna após alguma exposição ou conferência, embora em muitos casos não haver tempo para que todos inscritos consigam falar (pede-se, então, que dirijam sua intervenção por escrito à mesa da secretaria). A primeira atitude após a abertura oficial do evento foi a apresentação da pauta definida para a assembléia, simbolicamente votada e aprovada de forma unânime pelos bispos ao levantar o braço em sinal de acordo. A partir daí, abriu-se então espaço para a comunicação de prelados desejando abordar algum outro ponto específico, praticamente todos dizendo respeito a questões particulares de suas dioceses, salvo a proposta de consideração de um projeto de lei nacional regulamentando a união civil entre homossexuais. Da mesma forma, a intenção de "levar em conta” a opinião e avaliação de todo o grupo de bispos sobre o conjunto das atividades e da estrutura do evento é manifestada na realização de sua consulta através de questionários incluindo tópicos diversos como satisfação quanto à pontualidade, refeições, tema do retiro espiritual, orações, rendimento das reuniões, entre muitos outros. Uma vez compilados os dados, são então apresentados em forma de gráficos, ponto por ponto, no telão do auditório central e comentados muitas vezes em tom quase lúdico pelo secretário-geral. O mesmo tipo de situação se dá com a apresentação do relatório econômico anual da 
conferência, durante a qual o comentário jocoso de que "não houve dividendos para os bispos, evidentemente”, levou o auditório a rir efusivamente. ${ }^{9}$

No que tange aos membros do episcopado, a divisão das tarefas no interior da assembléia é orientada pelas diferentes funções de coordenação pastoral exercidas por parte dos bispos responsáveis. ${ }^{10}$ Assim, discussões específicas sobre dimensões de cada comissão pastoral davam-se entre os respectivos prelados e assessores nas salas menores, algumas extraordinariamente à noite, porém nunca se sobrepondo às reuniões gerais. Por outro lado, certos temas tiveram destaque e foram apresentados ao conjunto da assembléia, como é o caso da exposição sob o título "Amazônia: realidade e desafios para a evangelização", feita por um bispo membro da comissão especial criada para debater o assunto. No que tange aos outros participantes da assembléia compondo um grupo extenso e heterogêneo - cuja difícil identificação de pertencimento fizemos apenas de modo parcial em meio a uma quantidade expressiva de siglas que líamos nos crachás - são notadamente os religiosos e leigos com cargos de assessoria e os secretários regionais quem goza de maior prestígio no interior do grupo, dada a posição ocupada na estrutura administrativa, a proximidade com os bispos ou mesmo a autoridade sobre um determinado campo do saber legitimada por inserções nas esferas acadêmica e intelectual, no caso particular dos assessores. ${ }^{11}$ Membros dinâmicos na orientação e informação dos bispos durante as reuniões, até onde pudemos verificar, apenas

9 Ao presenciar o fato, lembramos imediatamente da seção de um texto de Pierre Bourdieu (1996, p. 163-203) intitulada justamente "O riso dos bispos", na qual o autor menciona o fato de os bispos que havia entrevistado em sua pesquisa rirem a cada vez que falavam a respeito da economia da Igreja, indicando os efeitos de recalque da objetivação da dimensão econômica (empresarial) próprios a universos antieconômicos como o universo religioso. Sou grato a Monique de Saint Martin por haver gentilmente colocado à minha disposição a íntegra da transcrição de diversas entrevistas com bispos franceses realizadas no quadro da pesquisa conduzida em conjunto com Pierre Bourdieu. A comparação com material por mim coletado junto aos bispos brasileiros apontou uma série de coincidências entre o funcionamento da alta esfera católica nos dois países.

${ }^{10}$ Lembramos que a CNBB está organizada ao longo do país em 16 conferências regionais, cada qual com sua estrutura administrativa (presidente, secretário, funcionários) e respectivas comissões pastorais e instituições correlatas, havendo ao mesmo tempo uma coordenação e comissões de nível nacional.

${ }^{11} \mathrm{O}$ número de assessores em nível nacional à época era em torno de 35. Dentre as resoluções sobre o novo estatuto da CNBB, tema central da reunião, justamente a tentativa de diminuição das influências e da intermediação de assessores e auxiliares entre Vaticano e prelados foi percebida como a mais polêmica, segundo depreendemos de conversas com alguns clérigos e também destacado pela imprensa (Farah, 2001).

Horizontes Antropológicos, Porto Alegre, ano 13, n. 27, p. 145-164, jan./jun. 2007 
esses últimos têm a oportunidade de se expressarem publicamente no evento, na condição de especialistas. À baixíssima presença feminina entre as participantes na assembléia, como seria previsto - incluindo representantes de órgãos vinculados à CNBB e algumas secretárias de bispos - contrapunha-se o predomínio de mulheres, sobretudo de religiosas, na execução geral de tarefas organizativas e braçais exigindo dinamicidade (recepção, logística, distribuição de materiais, imprensa institucional).

O respaldo dado à intervenção e à própria presença de assessores leigos “notáveis” indica a importância adquirida pela figura do "intelectual da Igreja” na estrutura da instituição, ao mesmo tempo em que permite vislumbrar em parte a imagem dominante que a conferência procura impor tanto à sociedade quanto aos seus próprios membros. Se não há nada de surpreendente na discussão aberta de temas próprios à "agenda nacional” - "política”, “economia”, "miséria”, "escândalos", "ecologia” - no seio de uma instituição cuja participação nas disputas sociais pela definição dessa agenda tem sido constante há mais de três décadas e a partir da qual ela se legitima fortemente, interessa observar as formas de explicitação dessa discussão, seus termos e efeitos mais visíveis. Do mesmo modo, cabe situá-la na dinâmica do conjunto das atividades da assembléia, as quais oscilam patentemente entre uma linha administrativo-institucional, "interna”, englobando, por exemplo, as decisões sobre funcionamento da conferência e distribuição do poder, e outra linha composta pelas formas de inserção estratégica da Igreja e sua atualização com as pautas sociais, todas essas atividades entremeadas por rituais religiosos unificando seus propósitos.

Nessa ótica, uma indicação da relevância do lugar ocupado pela "temática social” e a sintonia da instituição com seu repertório é a longa exposição (e a reação causada), nos momentos iniciais da assembléia, feita por um conhecido "sociólogo da religião", leigo, e assessor da CNBB, sob o título "Análise de Conjuntura”. Pretendendo oferecer uma "chave de leitura da realidade”, o texto lido quase na íntegra e também distribuído em plenário, aborda “criticamente" uma quantidade grande de tópicos entendidos como "principais questões da conjuntura brasileira desde 1989”, para em seguida “sinalizar alternativas” envolvendo a ação da Igreja. ${ }^{12}$ Após os aplausos da assembléia, manteve-se o

12 Como diz esse trecho na introdução, "esta análise traz uma interpretação para a crise econômica, social e política do Brasil. Por isso mesmo, mais do que um resumo dos principais acontecimentos desde a última Assembléia, ela quer oferecer uma chave de leitura da realidade”. Entre os tópicos

Horizontes Antropológicos, Porto Alegre, ano 13, n. 27, p. 145-164, jan./jun. 2007 
tom grave da fala anterior na série de comentários à que tiveram direito de fazer no púlpito os bispos, tratando-se de adesões e de complementos às "críticas" sobre a "conjuntura nacional”, corroboradas por propostas relativamente vagas de "soluções" ou "respostas" a partir de uma ação "evangélica”. Funcionando como uma sinalização da "pauta social" em torno da qual giraria o evento, esse "diagnóstico” claramente pessimista e duro em relação ao contexto do país, e mesmo do cenário mundial, situado na abertura da assembléia, parece também ter servido de instrumentalização aos discursos dos bispos não apenas nas reuniões, mas igualmente em entrevistas e conversas. ${ }^{13}$ Por outro lado, a exposição de assessores falando em nome da instituição à mídia em entrevistas coletivas agendadas pela CNBB, sozinhos ou acompanhados de bispos, reforça uma percepção de apresentação estratégica de uma imagem "unívoca” da conferência a respeito de temas “candentes” do país. Entre essas situações, destacamos a entrevista dada sozinho pelo sociólogo responsável pela "análise de conjuntura”, a entrevista com o assessor ("professor" e "escritor") sobre assuntos da Amazônia acompanhado dos três bispos membros da comissão especial e, ainda, a entrevista concedida por um "intelectual” de reconhecimento nacional sobre "corrupção política".

Os cuidados com a preservação da imagem de unidade do episcopado, e da Igreja, de um modo geral, também são perceptíveis na atitude de evitar a divulgação de tomadas de posição individual ou de qualquer informação sugerindo divergências entre o grupo. Exemplo claro dessas precauções foi a exigência de a imprensa retirar-se do auditório quando os bispos fariam uma "declaração sobre o momento atual do país”. Ao ser vedada a presença de pessoas não pertencendo institucionalmente à conferência, resguardava-se tanto o processo de apresentação do documento, feita por prelados e não por assessores, quanto as manifestações individuais que se seguiriam, buscando-se preservar a visão de integridade e de unanimidade de decisão sobre o grupo episcopal. Por outro lado, pouco após essa sessão a portas fechadas, um resumo do

abordados estão: "estabilidade da moeda”, "perda de densidade ética”, "a fragmentação da base política do Governo e as perspectivas eleitorais", "a crise econômica", "crise energética e ameaça de 'apagão'”, "contexto externo: a crise de hegemonia dos EUA", "plebiscito sobre a dívida externa”, "clamores do semi-árido", "o acompanhamento da lei contra a corrupção eleitoral” (CNBB, 2001).

${ }^{13}$ Percebemos a referência ao texto de "análise da conjuntura" tanto nos depoimentos de alguns dos bispos que entrevistamos quanto nas declarações de outros prelados à imprensa e mesmo em rodas informais de conversação.

Horizontes Antropológicos, Porto Alegre, ano 13, n. 27, p. 145-164, jan./jun. 2007 
documento foi divulgado pela assessoria de imprensa na forma de release com duas páginas, sendo então fornecida a posição oficial da CNBB. ${ }^{14} \mathrm{O}$ material informa que a "declaração" contém quatro páginas e retoma seus "principais pontos", deixando ver que o documento dos bispos trata basicamente dos mesmos assuntos elencados na "análise de conjuntura" apresentada não fazia muito. No entanto, a considerar pelo resumo, ao contrário do documento anterior centrado num vocabulário exclusivamente leigo e fartamente calcado em dados estatísticos, relatórios de institutos de pesquisa, jornais -, nesse caso, chama atenção a múltipla referência a citações de palavras do papa, a um documento da Conferência de Puebla e, ainda, a um trecho da Bíblia.

Todas as indicações levam a crer que na reunião privativa a CNBB apenas disse com sua própria voz, e à sua maneira, aquilo que já havia dito publicamente pela voz de um de seus "intelectuais", porém agora com grau de comprometimento maior, posto que apresentada como “declaração” e feita em nome da conferência. A série de providências visando a escamotear qualquer relação de conflito, crítica direta ou divergências no interior do episcopado segue uma das lógicas constitutivas do universo religioso que é a eufemização das relações sociais. Se a "tradicional” tensão fundamental - jamais admitida publicamente - no seio do episcopado gira em torno da definição das tarefas competentes à Igreja e às formas de realizá-las, simplificada na fórmula de posições em favor de uma instituição mais voltada à "administração dos bens espirituais” e preocupada com “assuntos internos”, ou então, ao contrário, uma Igreja mais "engajada” em "temas sociais” e que se manifesta sobre tudo o que diz respeito ao ser humano, e não apenas sobre a "religião”, todo esse suposto debate permanece intangível na assembléia. Apesar de esforços os mais variados, não conseguimos quebrar o tabu do tema em nenhuma conversa privada com prelados, cujas evasivas apenas confirmaram haver posições distintas. A questão se complexifica mais pelo fato de a posição oficial da Igreja ser domi-

\footnotetext{
${ }^{14}$ Como se lê no primeiro parágrafo do material: "Em uma Declaração sobre o Momento Atual do País com o título 'Brasil: Apreensões e Esperanças’, os Bispos Católicos, reunidos na 39a Assembléia Geral da CNBB, realizada em Itaici - Indaiatuba, de 12 a 21 de julho de 2001, em São Paulo, expressaram 'suas apreensões diante do difícil momento do país', mas também suas esperanças, partilhando seu compromisso de pastores” (CNBB, [s.d.], grifo no original). Chama atenção o uso de itálico na palavra “do” na frase “apreensões diante do difícil momento do país”, procurando-se evitar interpretações de que a dificuldade referida dissesse respeito à instituição católica, caso tivesse sido empregada a expressão no país.
}

Horizontes Antropológicos, Porto Alegre, ano 13, n. 27, p. 145-164, jan./jun. 2007 
nada por um discurso marcadamente "engajado" nas "questões sociais” (“denúncia social”, "crítica” a uma variedade de temas, envolvimento direto em manifestações, como o "plebiscito sobre a dívida externa”). Ou seja, se é quase impensável que algum bispo viesse a declarar publicamente, ou mesmo em privado a um pesquisador desconhecido, seu desacordo com a "linha social" dominante da instituição - o que colocaria em xeque um dos princípios de legitimação mais fortes do grupo -, praticamente todas as oportunidades de apreensão dessas posições divergentes ficam bloqueadas.

\section{Referências}

AZZI, Riolando. O episcopado brasileiro frente à Revolução de 1930. Síntese, v. 5, n. 12, p. 47-78, jan./mar. 1978.

AZZI, Riolando. Em prol de uma nova ordem: a posição do episcopado brasileiro na década de 1970-1980. Síntese, v. 8, n. 22, p. 49-82, maio/ago. 1981.

BOURDIEU, Pierre. Genèse et structure du champ religieux. Revue Française de Sociologie, v. 12, n. 3, p. 295-334, 1971.

BOURDIEU, Pierre. La distinction: critique sociale du jugement. Paris: Minuit, 1979.

BOURDIEU, Pierre. A economia dos bens simbólicos. In: BOUDIEU, Pierre. Razões práticas. Campinas: Papirus, 1996. p. 163-203.

BOURDIEU, P.; SAINT MARTIN, M. de. La sainte famille: l'épiscopat français dans le champ du pouvoir. Actes de la Recherche en Sciences Sociales, n. 44-45, p. 2-53, nov. 1987.

BRUNEAU, Thomas. O catolicismo brasileiro em época de transição. São Paulo: Loyola, 1974.

BRUNEAU, Thomas. Church and politics in Brazil: the genesis of change. Journal of Latin American Studies, n. 17, p. 271-293, 1985.

CNBB. Análise de conjuntura. [Texto para a 39a Assembléia Geral]. 2001. Mimeografado. $15 \mathrm{p}$.

CNBB. Release para imprensa. [s.d.]. 2 p.

DELLA CAVA, Ralph. Igreja e Estado no Brasil do século XX: sete monografias recentes sobre o catolicismo brasileiro-1916/1964. Novos Estudos-CEBRAP, n. 12 , p. 5-52, 1975. 
DELLA CAVA, Ralph. Política a curto prazo e religião a longo prazo: uma visão da Igreja católica no Brasil (em abril de 1978). Encontros com a civilização brasileira, n. 1, p. 242-256, jul. 1978.

FARAH, Paulo Daniel. Novo estatuto da CNBB concentra poder. Folha de $S$. Paulo, São Paulo, p. A13, 22 jul. 2001.

LIMA, Luiz. G. de Souza. Evolução política dos católicos e da Igreja no Brasil. Petrópolis: Vozes, 1979.

LÖWY, Michael. Rapports entre le religieux et le politique en Amérique Latine. Archives de Sciences Sociales des Religions, n. 114, p. 61-66, avril-juin 2001.

MAINWARING, Scott. Igreja católica e política no Brasil (1916-1985). São Paulo: Brasiliense, 1989.

MARIN, Richard. Dom Hélder Câmara: les puissants et les pauvres. Paris: Les Éditions de L'Atelier: Éditions Ouvrières, 1995.

MICELI, Sérgio. A elite eclesiástica brasileira. Rio de Janeiro: Bertrand Brasil, 1988.

MORAIS, João F. Régis de. Os bispos e a política no Brasil: pensamento social da CNBB. São Paulo: Autores Associados: Cortez, 1982.

ROUSSEAU, André. Les classes moyennes et l'aggiornamento de l’Église. Actes de la Recherche en Sciences Sociales, n. 44-45, p. 55-68, nov. 1982.

SEIDL, Ernesto. A elite eclesiástica no Rio Grande do Sul. Tese (Doutorado em Ciência Política)-Programa de Pós-Graduação em Ciência Política, Universidade Federal do Rio Grande do Sul, Porto Alegre, 2003.

SERBIN, Kenneth. Diálogos na sombra. São Paulo: Companhia das Letras, 2001.

VASSORT-ROUSSET, B. Les évêques de France en politique. Paris: Presses de la Fondation Nationale des Sciences Politiques, 1986.

VASSORT-ROUSSET, B. Positions politiques des évêques français Projet, n. 208, p. 11-20, 1987. 